MARLON G. JOSE,

MA, RN

Department of Education,

City of Balanga, Philippines

JUANITO C. LEABRES JR.,

Ed.D., RN

Wesleyan University,

Cabanatuan City, Philippines

https://orcid.org/0000-0003-

2192-4483

ALVIN V. NUQUI, Ph.D., PTRP

La Consolacion University,

Malolos City, Philippines

JESSIE C. NOGOY, MA, RN

Angeles University Foundation,

Angeles City, Philippines

RENE E. PUDADERA, MA, RN

Ramon Magsaysay Technological University,

Zambales, Philippines

WILFREDO RAMOS Ed.D., RN

Wesleyan University, Cabanatuan City, Philippines

Corresponding author's email: junfaithbap@gmail.com

\section{Maternal and Infant Care Beliefs and Practices of Aeta Mothers in Central Luzon, Philippines}

\section{Abstract}

Background: This study attempts at understanding the Aetas concept of maternal and infant care, specifically, beliefs and practices of Aeta mothers during pregnancy, childbirth and care of the infant.

Methodology: Qualitative descriptive design was utilized in this research. Forty Aeta mothers were informants of this study selected via purposive sampling. Participant observation, formal and informal interviews and examination of relevant documents were the instrument for data collection.

Findings: Most respondents were between 16-27 years old, from the province of Zambales, with two pregnancies and one living child. The majority had home deliveries attended by traditional birth attendants or next of kin and had visits to the Rural Health Units for prenatal check-up. It was found that the most Aeta mothers usually visit the Rural Health Unit in their second trimester. The mothers also rely on traditional beliefs and practices passed on from elders of the community particularly on diet, hygiene, and faith in God, preparation prior to delivery, cord care and use of placenta.

Conclusion: The findings showed that majority of the Aeta mothers interviewed adhered to some form of belief and practice that were passed to them by their elders.

Implication: Stakeholders such as government and nongovernment organizations should pursue promoting and enriching beliefs and practices of the Aeta and reinforcing 
programs with an emphasis on indigenous minorities to follow safe delivery and motherhood practices that are culturally acceptable.

Keywords: Aeta, health beliefs and practices, perinatal, pregnant women, safe delivery

\section{Introduction}

$\mathrm{n}$ the Philippines, traditional maternal and infant care beliefs and practices are still dominant in contemporary Filipino culture and are perpetuated by close female family relatives especially by indigenous people in the rural, remote and far-flung areas. For these underdeveloped and sometimes inaccessible areas, deep hold of traditional pre-Christian folk beliefs and animism characterized these ethnic communities (Palispis, 2012). The Aetas being one of the most prominent ethnic minority groups found in the Philippines that have held on to their cultural beliefs. Understandably, this indigenous group has been inhabiting the archipelago even before the Spanish colonizers came though despite few accounts have been written. Early writers described them as "small blacks" which roamed in the mountains living on roots and game which they killed with bows and arrows (David, 2011). The Spaniards colonizers referred to them as "Negritos" or "Little Black One" being short, dark-skinned and kinky-haired. Today they known by different names: "Ayta", "Agta", "Atta", "Ati" and "Ita". These names are usually based on their geographical location, history, or relationship with other people and are spread over the island of Luzon, including the Visayas and Mindanao. Approximately, the Negrito numbers around 90,000 throughout the archipelago and are divided into 25 ethnolinguistic groups dispersed in bands from Luzon to Mindanao. The most numerous are those found in the island of Luzon. Perpetually pushed into the hinterlands of Central Luzon, mainly in the provinces of Zambales, Bataan and Pampanga, and in other parts of the country and rely on natural resources as their major source for their economic activity such as foraging, hunting wild animals, livestock and poultry production, farming, making and selling hard brooms (Tindowen, 2016) and conditional cash transfer programs of the government such as the Pantawid Pampamilya Pilipino Program (4Ps). Exploring and identifying traditional maternal and infant care beliefs and practices of the Aeta mothers was the main aim of this study. Specifically, this study focused on understanding their unique beliefs and practices as well as discovering and appreciating their underlying meanings.

\section{Methods}

\section{Research Design}

Qualitative descriptive method was utilized in this research with semi-structured interview as the main tool in gathering data and using non-participant observation, interview and documents analysis. In this study, the researcher relied on observation, interviews, and archival analysis 
to provide deep understanding of what is studied.

\section{Locale of the Study}

Mothers from pre-determined Aeta communities in provinces comprising Central Luzon namely Aurora, Bataan, Bulacan, Nueva Ecija, Pampanga, Tarlac and Zambales were informants of this study. Areas and communities were chosen by consultations from local and national council of indigenous people offices, the concerned local government units, higher education institutions and tribal councils.

\section{Data Collection Procedure}

Prior permission from the council of elders and the tribal chieftain of each Aeta community was obtained as well as from local government units. Informed consent was gathered from informants before interview and due effort was made to clearly and fully explain the study based on their level of understanding. Interviews and observation in the community in the course 6 months was the main instrument for data gathering. Local dialect was employed in communicating with the informants and field diary and recorder were used for documentation. Validation was done with key informants and chieftain of the respective community. Confidentiality and anonymity were maintained throughout the conduct of the study. Informants of this study were chosen according to the following criteria: must be an Aeta women who have been pregnant and had at least one child alive and have been in the community since birth.

Forty (40) were the informants from indigenous Aeta communities in from the provinces of Central Luzon. Almost half were aged 16-27 years old. Most are from the Province of Zambales, having been pregnant twice and with one child alive. Majority of the mothers had home deliveries attended by traditional birth attendants. Analysis of the data involved collecting and documenting the data by the informants, transcribing the data and identifying the major themes.

\section{Findings}

\section{On Being Pregnant}

Most of the informants expressed a passive attitude with regards to pregnancy. According to most of them, they will know they were pregnant when they feel their abdomens getting bigger or heavier although some younger informants say they suspected to be with a child when they stopped having their monthly menstruation. It is therefore not uncommon to see Aeta mothers visiting the rural health unit at least once or twice for their prenatal checkup but well beyond the first trimester of pregnancy. The mothers described the check up as the midwives "touching their abdomens with their palms" then they will be given vitamins for free. As one informant said, "Kung ano man ang ipagkaloob 
ng Diyos..." ("Whatever God gives...") The response captures the attitude that most Aetas have not only towards pregnancy but other circumstances in their lives beyond their control.

According to the informants, their daily physical activities did not change even though they were pregnant. Being an Aeta, a woman is expected to help their husbands earn a living. They perform arduous tasks such as planting crops, harvesting "lagundi" and other herbs in the forest to be sold to merchants or doing strenuous chores like fetching water and carrying them in their heads at the same time. The Aeta women do not have restrictions in their daily activities and any harmful consequence is usually attributed to an act of God.

There is no major diet restrictions described by the informants except for anything sour. They believe that the sense of smell plays a significant role during the prenatal phase of pregnancy. The Aeta mothers mentioned that the smell or ingesting vinegar or pepper ingestion is forbidden because it causes mental problems. "Sa amin po suka, sili. (For us, its vinegar, pepper). Yun daw nakakabaliw" (It can cause mental problems)...

The informants can have whatever food they like but added that eating uncooked whole native eggs while pregnant helps in easy delivery of the baby. The importance of eating green, leafy vegetables was also stressed out by the participants. The Aetas eat to survive and will take whatever is available. Being an ethnic cultural minority, this attitude has been engrained in them which enabled them to survive during difficult times. Grey (2016) attributes this to the Aetas being driven into "a socially, politically, and economically disadvantageous position vis a vis the dominant lowland populations". This was further intensified by isolation of their upland habitat and by a lifestyle much unlike that of the lowlands, racial differences and sociopolitical indifference towards them aggravated after the eruption of Mt. Pinatubo.

The Aeta women preparation of the "banigan" (beddings) is still done in some areas prior to delivery especially for mothers who gives birth by themselves with the husband or significant kin present only for support in some provinces. The "banigan" is described as a mat where all the things that will be needed is within reach such as the instrument for cutting the umbilical cord (the "buho" or skin of bamboo sliced to give it a sharp edge), the container with warm water for washing the infant and clean set of clothes and the dried grounded coconut mixed with alcohol which they apply around the umbilicus. Variations include a high pillow made of sack filled with clothes to elevate the head and a rope to hold during delivery and foot stools for support as also being essential. Superstitious beliefs still abound such as massaging their abdomen in the river in the early morning so that the baby comes out head first. Some of the Aeta mothers believe in "usog" but describes it as an evil eye or the greeting that unconsciously inflicts illness to another. This is contrary to the study of Grey (2016) which described this act as "tuyaw" whereas "usog" is the term used for the dialect term for the chant (Grey, 2016). Martinez, Cortez and Contreras (2019) however agree in that "usog" is described as a transmittable mystical force unintentionally inflicted by humans through an eye or physical contact; thereby producing physical symptoms among its victims. 


\section{Giving Birth}

When in labor, the Aeta mothers use chili pepper leaves and stroke the abdomen and the lower back following the sign of the cross to avoid premature labor. The informants also wrap a piece of cloth or "bigkis" above the waist just below the ribs so that the baby may continue its descent. On the other hand, when contractions become frequent and painful, the expectant mother is made to take one fresh whole egg from a native chicken or "tanglad" (lemon grass) in the belief that this will hasten childbirth.

Self-assisted delivery by the Aeta mothers is done by assuming a slightly slanted sitting position, with feet pressed upon a stool and both hands holding a rope used to press down when doing the act of "pushing" the baby.

The use of "buho" (a slice of bamboo bark used to cut the umbilical cord) is still practiced in cutting the cord of their newborns in almost all of the provinces. Furthermore, some of the informants still apply a mixed of powdered coconut shell or coconut meat with alcohol on the navel believing to prevent wound infection. For the majority of them, alcohol is now the only one used for drying of the cord. The use of the "buho" is similar to the "runo" of the Kalanguya used in cutting the cord. Low and middle income countries have traditionally used a variety of substances in caring for the cord of which the desire to promote healing and hasten cord separation are the underlying beliefs related to application of substances to the umbilical cord (Coffey \& Brown, 2017).

To give birth, all the informants expressed having a sense of spirituality or faith in God as a necessity which they attribute to influences by Catholicism or other religious sects. They believe that a trusting faith will lead to a safe delivery and healthy child. Moreover, almost all of the mothers had home deliveries. Reasons such as to save money for future use or the lack of it, the distance or inaccessibility of their place of residence as well as adherence to traditional beliefs were mentioned why they chose to do so. Most delivered by themselves in the presence of their significant kin while some by native birth attendants. The elderly informants believed that complications are caused by chemicals in foods brought by the modernization.

Most Aeta mothers said they no longer visit the health center after delivery. The native birth attendants usually visit and take care of them for 9 days. They also added that they utilized herbal medicines for their fast recovery. They are also prohibited to work hard for about 2 months.

Furthermore, the cord is wrapped and hanged beside the window or near the stove to dry. The informants mix the dried cord in water and given to the infant to treat ailments such as "taon" (term used for diarrhea with greenish stools) or fever. 
Based on the informants, the "inunan" (placenta) is either buried near or thrown in the river for varied reasons. Burying so the baby will not be "mainitin ang ulo" (hot-headed). On the other hand, the also believe that placenta buried to an area with flowing rain will make the baby tolerant to cold weather and will be cool-headed. This practice is especially common in the provinces of Aurora, Nueva Ecija, Tarlac and Zambales as compared to the more "modern" provinces of Bataan, Bulacan and Pampanga.

The mother who gave birth are given hot porridge or hot drinks while sour food is strictly avoided after for the first month or until there is no more blood discharge. This includes vinegar among others as they believe this causes insanity and "binat".

Majority of the Aeta mothers follow a prescribed period of $5-7$ days after giving birth before they are allowed to take a bath. According to them, this is to prevent "binat", a state characterized by having flu-like symptoms. The first bath is described as a warm bath with a concoction of herbs such as guava, or lagundi leaves. This for them is to renew their strength which they have exhausted during the delivery. This practice is strong especially in the provinces of Bataan, Nueva Ecija, Tarlac and Zambales.

\section{Breastfeeding}

Most of the informants have all breastfed their newborns and are prohibited to eat salty foods which they believe hinders the flow of milk. Eating vegetables is also believed to improve its flow. Furthermore, they breastfeed their newborns for 6 months or until they eventually wean themselves. Weaning is by using chili on her breast to wean her child. They all agree that breastfeeding is the best way to promote emotional and physical bonding with their newborn.

\section{Conclusion}

From the findings include, it is shown that majority of the Aeta mothers interviewed adheres to some form of belief and practice and that these beliefs and practices were taught to them by the elders who by most practiced it from generations to generations. Beliefs regarding "hot" and "cold" and relapse still dominate the mothers understanding about delivery. Though health workers and health programs have created an awareness regarding safe pregnancy, there are those who still cling to the old ways. Factors such as the remoteness and accessibility of their community, lack of finances, lack of health centers on workers within their community as reasons for some of the Aeta not being able to access health programs. 


\section{Implications}

1. Rural Health midwives are advised to have regular visits to the Aeta mothers to their respective communities. This will assist the mothers in monitoring their pregnancies to avoid possible problems.

2. A regular health promotion seminar be conducted to the community especially to the women to educate them about pregnancy and other significant health concerns.

3. The perinatal health practices of the indigenous mothers are ingenious and unique. However, some traditions may result in possible harm to the Aetas themselves. Hence, health dissemination and promoting understanding of the Aetas' practices should be a priority.

4. A thorough investigation of the culture of Aeta mothers through immersion be done to have a better understanding of the ethnographic background of their perinatal beliefs and practices.

\section{References}

Coffey, P. \& Brown, S. (2017). Umbilical cord-care practices in low- and middle-income countries: a systematic review. BMC Pregnancy and Childbirth. 2017; 17(1). doi: 10.1186/s12884-017-1250-7

David, M. E., (2011). Aeta Mag-anchi's Cultural History, Concept of Time and Territoriality: Its Implications to Education. International Conference on Social Science and Humanity, 5, 112-116

Grey. E. (2016). Cultural Beliefs and Practices of Ethnic Filipinos: An Ethnographic Study. International Journal of Management and Social Sciences. 3(3), 739-748. doi: http://dx.doi.org/10.21013/jmss.v3.n3.p30

Martinez, R., Cortez, A. \& Contreras, V. (2019). Understanding the concept of Usog among the Aetas of Nabuclod, Pampanga, Philippines. Journal of Social Health. 2(1), 18-27.

Palacio, M. A., Palacio C. S., Ebuenga, L. C., Valladolid, E. S. (2014). Maternal-infant health beliefs and practices of mothers in resettlement sites in the province of Albay. International Journal of Technical Research and Application.

Palispis, E. S. (2012). Introduction to Sociology and Anthropology. Quezon City, Philippines: Rex Bookstore.

Tindowen, D. (2016). The Economic Life of the Aetas of Northern Philippines. Khazar Journal of Humanities and Social Sciences, 19(4), 97-109. 


\section{About the Authors}

Marlon G. Jose, MA, RN, is a former University Nurse and Clinical Instructor at Bataan Peninsula State University. At present, he is a public school nurse of the Department of Education, City of Balanga.

Juanito C. Leabres Jr., Ed.D., RN, is part time faculty of the College of Nursing and Allied Medical Sciences of Wesleyan University - Philippines and the Director of the Office for Extension Programs of Wesleyan University Philippines. He is a member of the Philippine Nursing Research Society - Nueva Ecija and currently holds the position of Vice President. An inductee of Sigma Honor Society of Nursing Pi lota, he is currently writing his dissertation for his Ph.D. in Nursing Education.

Alvin V. Nuqui, Ph.D., PTRP, is currently the Vice President for Academic Affairs, Executive Vice President and Dean of the Graduate School of La Consolacion University Philippines. He has published numerous paper in national and international journals and an international journal reviewer. He is also an accreditor and a member of the CHED Regional Quality Assurance Team.

Jessie C. Nogoy, MA, RN, is the acting Director of the Alumni Affairs and Placement Services of Angeles University Foundation and writes for the Compilation, the research publication of the AUF-College of Nursing.

Rene E. Pudadera, MA, RN, is the Dean of the College of Nursing of Ramon Magsaysay Technological University, Iba Campus. An active member of the Philippine Nurses Association (PNA) and the Association of Deans of Philippine Colleges of Nursing, Inc. (ADPCN)

Wilfredo Ramos, Ed.D., RN, has held numerous leadership positions at Wesleyan University Philippines in the past such as Coordinator for the College of Nursing, Director of the Alumni Affairs Office, Dean of the College of Nursing and Allied Medical Sciences as well as an officer and a member of the house of delegate of the Philippine Nurses Association - Nueva Ecija. He is also currently an accreditor for the Association of Christian Schools, Colleges and Universities (ACSCU). 